\title{
BAL fluid LDH activity and LDH isoenzyme pattern in lipoid pneu- monia caused by an intravenous injection of lamp oil
}

\author{
M. Drent*, N.A.M. Cobben*, R.F. Henderson**, J.A. Jacobs+, E.F.M. Wouters*, \\ M.P. van Dieijen-Visser ${ }^{++}$
}

BAL fluid LDH activity and LDH isoenzyme pattern in lipoid pneumonia caused by an intravenous injection of lamp oil. M. Drent, N.A.M. Cobben, R.F. Henderson, J.A. Jacobs, E.F.M. Wouters, M.P. van Dieijen-Visser. CERS Journals Ltd 1996.

ABSTRACT: A 30 year old man developed lipoid pneumonia after an injection of lamp oil.

In addition to "foamy" alveolar macrophages, bronchoalveolar lavage (BAL) fluid analysis showed an increased number of neutrophils. Moreover, lactate dehydrogenase (LDH) and alkaline phosphatase activities were elevated. The increase seen in LDH activity both in serum and BAL fluid was accompanied by shifts in the isoenzyme pattern in similar directions for both fluids. These findings suggest a pulmonary source for the temporary serum as well as BAL fluid LDH increase.

This case indicates the usefulness of bronchoalveolar lavage fluid analysis as a probe to detect pulmonary injury caused by a pneumotoxicant and, probably, to monitor recovery or deterioration.

Eur Respir J., 1996, 9, 2416-2418.
Depts of *Pulmonology, + Medical Microbiology and ${ }^{++}$Clinical Chemistry, University Hospital of Maastricht, Maastricht, The Netherlands. **Inhalation Toxicology Research Institute, Lovelace Biomedical and Environmental Research Institute, Albuquerque, New Mexico, USA.

Correspondence: M. Drent, Dept of Pulmonology, University Hospital of Maastricht, P.O. Box 5800, 6202 AZ Maastricht, The Netherlands

Keywords: Alkaline phosphatase, bronchoalveolar lavage, lactate dehydrogenase, lactate dehydrogenase isoenzymes, lipoid pneumonia, paraffin

Received: March 14 1996, Accepted after revision July 91996

\section{Case report}

A 30 year old man was transferred to our hospital from a local hospital. Eight hours before admission he had attempted suicide by injecting $10 \mathrm{~mL}$ of lamp oil (liquid paraffin) into a vein in his left elbow. On admission, no abnormalities were found. Over the following hours, the patient's respiratory condition deteriorated requiring mechanical ventilation.

Chest radiography revealed a diffuse reticulonodular infiltrative process. A bronchoalveolar lavage (BAL) was performed 2 days after admission. Simultaneously, blood samples were taken. No bacteria were seen on Gramstained preparations and culture of BAL fluid remained sterile. Further analysis of the BAL fluid revealed an increased number of cells $\left(32 \times 10^{4}\right.$ cells $\cdot \mathrm{L}^{-1}$; reference value for nonsmokers $10.3 \pm 1.5 \times 10^{4}$ cells $\left.\cdot \mathrm{L}^{-1}\right)$, predominantly polymorphonuclear neutrophils $(52 \%$; reference value for nonsmokers $1.3 \pm 0.2 \%$ ) [1]
Cell-free supernatant from BAL fluid as well as serum were assayed for lactate dehydrogenase (LDH) and alkaline phosphatase activities. Additionally, protein and albumin contents were determined in cell-free BAL fluid and serum. In serum, the total protein and albumin levels were decreased (table 1). LDH activity was increased in serum to $795 \mathrm{U} \cdot \mathrm{L}^{-1}$ (reference range $200-450 \mathrm{U} \cdot \mathrm{L}^{-1}$ ) $[2,3]$, as well as in BAL fluid $\left(115 \mathrm{U} \cdot \mathrm{L}^{-1}\right.$; reference range $\left.20-59 \mathrm{U} \cdot \mathrm{L}^{-1}\right)$ (table 1). Alkaline phosphatase activity in BAL fluid was high $\left(145 \mathrm{U} \cdot \mathrm{L}^{-1}\right.$; reference range $0-25 \mathrm{U} \cdot \mathrm{L}^{-1}$ ), whereas in serum it was within normal limits (table 1). At this moment, all other laboratory tests including liver function tests were normal. Moreover, on cytocentrifuged preparations of the BAL fluid stained with May-Grünwald-Giemsa (MGG; Merck, Darmstadt, Germany) numerous lipid-laden, "foamy" alveolar macrophages were seen.

The diagnosis lipoid pneumonia was based on the clinical picture and the cytological analysis of BAL fluid.

Table 1. - Biochemical characteristics of the case presented

\begin{tabular}{|c|c|c|c|c|c|c|c|c|}
\hline & $\begin{array}{l}\text { albumin } \\
\mathrm{g} \cdot \mathrm{L}^{-1}\end{array}$ & $\begin{array}{l}\mathrm{LDH} \\
\mathrm{U} \cdot \mathrm{L}^{-1}\end{array}$ & $\begin{array}{c}\text { LDH-1 } \\
\%\end{array}$ & $\begin{array}{c}\mathrm{LDH}-2 \\
\%\end{array}$ & $\begin{array}{c}\text { LDH-3 } \\
\%\end{array}$ & $\begin{array}{c}\text { LDH-4 } \\
\%\end{array}$ & $\begin{array}{c}\text { LDH-5 } \\
\%\end{array}$ & $\begin{array}{c}\text { AP } \\
U \cdot L^{-1}\end{array}$ \\
\hline Serum* & 19.9 & 795 & 9 & 27 & 22 & 14 & 28 & 108 \\
\hline Reference value range $^{+}$ & $35-55$ & $200-450$ & $19-30$ & $32-48$ & $12-22$ & $4-11$ & $5-13$ & $30-125$ \\
\hline BAL fluid & 0.082 & 115 & 3 & 10 & 20 & 32 & 34 & 145 \\
\hline Reference value range & $0.065-0.080$ & $20-59$ & $8-35$ & $15-30$ & $22-33$ & $14-27$ & $6-14$ & $0-25$ \\
\hline mean $\pm \mathrm{SEM}^{\ddagger}$ & $0.071 \pm 0.009$ & $28 \pm 5$ & $17 \pm 3$ & $23 \pm 2$ & $29 \pm 1$ & $20 \pm 2$ & $10 \pm 1$ & $9 \pm 3$ \\
\hline $\begin{array}{l}\text { Lung tissue } \\
\text { reference value§ }\end{array}$ & & & 10 & 20 & 30 & 25 & 15 & \\
\hline Fluid/serum ratio & $4.1 \times 10^{-3}$ & 0.15 & 0.38 & 0.38 & 0.92 & 2.38 & 1.18 & 1.34 \\
\hline
\end{tabular}

*: value at the time that BAL was performed; +: adapted from [2]; $\$$ : normal values of nonsmokers, adapted from DRENT et al. [1]; \$: adapted from LotT and NEMESZANSKY [3]. LDH: lactate dehydrogenase; AP: alkaline phosphatase; BAL: bronchoalveolar lavage. 
The patient was treated by supportive measures. By the time the patient's clinical condition had improved, the LDH activity in serum had gradually decreased and, finally, returned to normal. One month after admission, control chest radiography and high resolution computed tomography (HRCT) showed no signs of the earlier abnormalities, and all pulmonary function tests were normal.

\section{Discussion}

Lipoid pneumonia is a disorder caused mainly by inhalation or aspiration of liquid paraffin (mineral oil) or related hydrocarbon compounds [4-10]. A reliable diagnosis may be achieved by BAL fluid analysis and, more importantly, BAL avoids more invasive diagnostic procedures, such as lung surgical biopsies, for these often critically ill patients [7, 8]. Generally, this disorder does not require medical intervention. Although animal studies report the development of pulmonary damage following an intravenous injection of such pneumotoxicants [11], less is known about the effect of intravenous injection of paraffin in humans. Few case reports describing pulmonary damage after such injection were found $[12,13]$. As far as we know, this is the first human report describing LDH activity and LDH isoenzyme pattern in lipoid pneumonia.

Paraffins are noncorrosive, but may interact with pulmonary surfactant, which probably causes the damage to the alveolar walls $[7,10]$. Therefore, the alveolar/blood barrier is also damaged. Cellular enzymes in the extracelluar space, although of no further metabolic function, are still of benefit because they serve as indicators of disturbances of the cellular integrity induced by pathological conditions $[11,14,15]$. $\mathrm{LDH}$ is a cytoplasmic enzyme present in essentially all major organ systems, whose extracelluar appearance is used to detect cell damage or cell death. Due to its extraordinarily widespread distribution in the body, serum LDH is abnormal in a host of disorders $[3,16]$. Although the increase in total serum LDH activity is rather nonspecific, measurements of LDH activity in serum, pleural effusion, and, more recently, in BAL fluid have been reported to be valuable tools for investigating lung and pulmonary endothelial cell injury [17-24].

Elevations in lung tissue LDH activity and serum activity have been noted in many cases following exposure to pneumotoxicants, as well as other pathological conditions. This has been thought to be due to the influx of inflammatory cells [4, 17, 23]. Therefore, there can be leakage of $\mathrm{LDH}$ from the pulmonary interstitium to the blood. Because the ratio of $\mathrm{LDH}$ activity to albumin was much higher in the BAL fluid than in the serum, the increased LDH in BAL fluid cannot be due to simple leakage of serum into the alveolar space [18].

Remarkably, the increase in LDH activity both in serum and in BAL fluid was accompanied by shifts in the isoenzyme pattern in similar directions for both fluids. That is, there were major increases in the LDH-5 activity in both cases, some increase in LDH-4 activity, and decreases in LDH-1 and LDH-2 activity, respectively. Some increased LDH activity in the serum caused by this toxicant agent may come from damage to other organs, as pathological lesions of the spleen, liver, lymph nodes and bone marrow are reported, in addition to the lung $[8,10]$. However, the fact that the shift in pattern of the LDH isoenzymes in serum (increases in percentage of LDH-4 and especially LDH-5 activity, decreases in percentage of LDH-1 and LDH-2 activity) resembles that in the BAL fluid, suggests that the lung was the major source of the serum LDH.

The source of the LDH activity from the lung may be inflammatory cells, such as the alveolar macrophage, for which the most prominent LDH isoform is the LDH-5 isoenzyme $[11,14,25]$. In fact, it is tempting to hypothesize that alveolar macrophages would be rapidly recruited to rid the lung of the lipid, and the elevated LDH-5 activity both in the BAL fluid and the serum is due to the rapid turnover (death) of alveolar macrophages in their clean-up efforts [25]. Since the alveolar macrophages cannot metabolize the chemically inert, nonsaponifiable oil, they disintegrate after some time and liberate the intracellular oil into the alveoli, a target for a new generation of alveolar macrophages [7, 25]. When the mucociliarly transport becomes depressed, a vicious circle may be set up, which accounts for the possible chronicity of this disease and the development of interstitial fibrosis [7].

Schultze et al. [11] reported that an intravenous injection of a small dose of monocrotaline pyrrole (MCTP), a putative, toxic metabolite of monocrotaline, selectively caused delayed and progressive lung injury, whilst sparing other organs [11]. The increase in total LDH activity in cell-free BAL fluid was due to increased LDH-4 and LDH-5. Presuming that lung tissue values are comparable with BAL fluid levels (and normal values of the LDH-isoenzyme pattern in BAL fluid in humans are not yet available due to technical problems) the values for LDH-isoenzyme activity pattern in lung tissue are presented in table $1[3,11]$. The changes induced in the LDH-isoenzyme pattern suggest that the increased LDH activity of cell-free BAL fluid arose from lung tissue. The isoenzyme pattern of pulmonary endothelial cells was consistent with a contribution of pulmonary endothelium injured by MCTP. Inflammatory cells in the lungs and leakage of plasma into the air spaces may have made a small contribution to cellfree BAL fluid LDH activity, but these sources alone cannot explain the alterations in LDH isoenzyme pattern that occurred in cell-free BAL fluid after treatment of rats with MCTP. In the case presented, the increased LDH activity in serum as well as in BAL fluid is indicative of pulmonary inflammation. Moreover, clinical improvement, with a regression of the inflammatory reaction, was related to a gradually decrease of the LDH activity in serum (data not shown).

It is tempting to speculate that the proliferation of type II pneumocytes or bronchial epithelial cells might participate in the remodelling process of the lung [14, $23,26,27]$. The high alkaline phosphatase activity in this case is in agreement with this hypothesis. Namely, alkaline phosphatase activity has been observed histochemically in type II pneumocytes which have been shown to proliferate following exposure to pulmonary toxicants and to replace the damaged type I pneumocytes $[14,23,26]$. Therefore, increases in alkaline phosphatase levels in BAL were noted as a marker of type II 
cell damage and/or proliferation $[14,26]$. It is wellknown that the type II pneumocyte is important in the repair of alveolar epithelium after injury, and responds to oxidant stress (such as hyperoxia) [14, 22, 26, 27]. It was suggested that adaptive responses to oxidant injury occur in type II pneumocytes after exposure to minerals.

In conclusion, in this patient, there was no clinical or laboratory evidence to indicate hepatic, myocardial, or apparent source other than the lungs for the temporary elevation in serum and bronchoalveolar lavage fluid lactate dehydrogenase (especially LDH-4 and LDH-5) activity. Furthermore, in agreement with previously reported animal studies, this case indicates the usefulness of lactate dehydrogenase and alkaline phosphatase analysis in bronchoalveolar lavage fluid as a probe to detect inflammatory pulmonary injury causing cell damage due to a pneumotoxicant, and also to monitor repair and recovery in humans. Future studies are needed to clarify the possible relationship between lactate dehydrogenase and alkaline phosphatase activity and outcome in patients suffering from inflammatory lung diseases, as well as their role in follow-up regarding prognosis and evaluation of medical treatment.

\section{References}

1. Drent M, Wagenaar SjSc, Velzen-Blad van $\mathrm{H}$, et al. Relationship between plasma cell levels and profile of bronchoalveolar lavage fluid in patients with subacute extrinsic allergic alveolitis. Thorax 1993; 48: 835-839.

2. Beckman Instruments Inc. Lactate dehydrogenase and isoenzymes. Synchron CX Systems Chemistry Information, 1993.

3. Lott JA, Nemeszansky E. Lactate dehydrogenase (LD). In: Lott, JA, Wolf PL, eds. Clinical Enzymology: a CaseOriented Approach. New York, Field, Rich \& associates. 1986; pp. 213-244.

4. Weill H, Ferrans VJ, Gay RM, Ziskind MM. Early lipoid pneumonia: roentgenologic, anatomic and physiologic characteristics. Am J Med 1964; 36: 370-376.

5. Spatafora M, Bellia V, Ferrera G, Genova G. Diagnosis of a case of lipoid pneumonia by bronchoalveolar lavage. Respiration 1987; 52: 154-156.

6. Chastre J, Brun P, Soler P, et al. Acute and latent pneumonitis after subcutaneous injections of silicone in transsexual men. Am Rev Respir Dis 1987; 135: 236-240.

7. Lauque D, Dongay G, Levade T, et al. Bronchoalveolar lavage in liquid paraffin pneumonitis. Chest 1990; 98: $1149-1155$.

8. Levade T, Salvayre R. Chemical analysis of the bronchoalveolar washing fluid in the diagnosis of liquid paraffin pneumonia. J Clin Chem Clin Biochem 1987; 25: 45-48.

9. Gondouin A, Manzoni Ph, Ranfaing E, et al. Exogenous lipid pneumonia: a retrospective multicentre study of 44 cases in France. Eur Respir J 1996; 9: 1463-1469.

10. Klein BL, Simon JE. Hydrocarbon poisonings. Pediatr Clin North Am 1986; 33: 411-419.
11. Schultze AE, Gunaga KP, Wagner JG, et al. Lactate dehydrogenase activity and isoenzyme pattern in tissues and bronchoalveolar lavage fluid from rats treated with monocrotaline pyrrole. Toxicol Appl Pharmacol 1994; 126: 301-310.

12. Neeld EM, Limbacher MC. Clinical pneumonitis after the intravenous injection of hydrocarbon. Radiology 1987; 129: 36.

13. Bhagat R, Holmes IM, Kulaga A, Murphy F, Cockcroft DW. Self-injection with olive oil; a cause of lipoid pneumonia. Chest 1995; 107: 875-876.

14. Henderson RF, Scott GG, Waide JJ. Source of alkaline phosphatase activity in epithelial lining fluid of normal and injured F344 rat lungs. Toxicol Appl Pharmacol 1995; 134: 170-174.

15. Roth RA. Effect of pneumotoxicants on lactate dehydrogenase activity in airways of rats. Toxicol Appl Pharmacol 1981; 57: 69-78.

16. Glick JH. Serum lactate dehydrogenase isoenzyme and total lactate dehydrogenase values in health and disease, and clinical evaluation of these test by means of discriminant analysis. Am J Clin Path 1969; 52: 320-328.

17. Henderson RF, Driscoll KE, Harkema JR, et al. A comparison of the inflammatory response of the lung to inhaled versus instilled particles in F344 rats. Fundam Appl Toxocol 1995; 24: 183-197.

18. Hoffman RM, Rogers RM. Serum and lavage lactate dehydrogenase isoenzymes in pulmonary alveolar proteinosis. Am Rev Respir Dis 1991; 143: 42-46.

19. Smith RL, Ripps CS, Lewis ML. Elevated lactate dehydrogenase values in patients with Pneumocystis carinii pneumonia. Chest 1988; 93: 987-992.

20. Matusiewicz SP, Williamson IJ, Sime PJ, et al. Plasma lactate dehydrogenase: a marker of disease activity in cryptogenic fibrosing alveolitis and extrinsic allergic alveolitis? Eur Respir J 1993; 6: 1282-1286.

21. Krugten van M, Cobben NAM, Lamers RJS, DieijenVisser van MP, et al. Serum LDH: a marker of disease activity and its response to therapy in idiopathic pulmonary fibrosis. Neth J Med 1996; 48: 220-223.

22. DeRemee RA. Serum lactic dehydrogenase activity and diffuse interstitial pneumonitis. J Am Med Assoc 1968; 204: 103-105.

23. Vijeyaratnam GS, Corrin B. Pulmonary histiocytosis simulating desquamative interstitial pneumonia in rats receiving oral iprindole. J Pathol 1972; 108: 105-113.

24. Quist J, Ross A. Serum lactate dehydrogenase (LDH) in Pneumocystis carinii pneumonia, tuberculosis, and bacterial pneumonia. Chest 1995; 108: 415-418.

25. Bansal SK, Kaw JL. Lactate dehydrogenase isoenzymes in macrophages and serum during the development of pulmonary silicosis in the rat. Toxicol Lett 1981; 7: 279-283.

26. Janssen YMW, Marsh JP, Absher MP, et al. Expression of antioxidant enzymes in rat lungs after inhalation of asbestos or silica. J Biol Chem 1992; 267: 10625-10630.

27. Panus PC, Matalon S, Freeman BA. Responses of type II pneumocyte antioxidant enzymes to normoxic and hyperoxic culture. In Vitro Cell Dev Biol 1989; 25: 821-829. 